\title{
Velhice bem-sucedida: aspectos afetivos e cognitivos
}

\author{
Marina Liberalesso Neri ${ }^{1}$
}

Neri, A. L. \& Yassuda, M. S. (Orgs.). (2004). Velhice bem-sucedida: aspectos afetivos e cognitivos. Campinas: Papirus, $224 \mathrm{p}$.

O declínio da crença de que uma velhice bemsucedida associa-se a eventos sobrenaturais, à sorte, ou ao coroamento de uma vida virtuosa coincidiu com a ampliação da crença na ciência como a fonte mais confiável de compreensão dos fatos naturais. Assim, o ser humano passou a conviver com cada vez mais informações sobre fatores que conduzem a uma velhice bem ou malsucedida. É dado científico que a velhice caracteriza-se pelo declínio das funções biológicas, da resiliência e da plasticidade. Ainda que ocorram de forma diferenciada entre pessoas, as perdas que caracterizam a velhice provocam o aumento da dependência dos indivíduos em relação aos elementos da cultura e da sociedade. Por outro lado, e ao contrário do que se pensa, é possível a preservação e ganhos evolutivos em determinados domínios do funcionamento, como o intelectual e o afetivo, sendo este último capaz de atuar de maneira compensatória sobre as limitações cognitivas.

Este livro apresenta conceitos e dados empíricos sobre o funcionamento normal e patológico dos principais processos intelectuais, afetivos e motivacionais na velhice e sugere soluções para que indivíduo e ambiente possam contribuir para a continuidade e ganhos nesses aspectos, o que se traduz em velhice bem-sucedida. Escrito por professores e alunos de Pós-Graduação em Gerontologia da Unicamp, visa veicular conhecimentos científicos sobre como envelhecer bem e contribuir para a melhoria da qualidade dos serviços e das políticas sociais para os idosos no Brasil.

No 1 capítulo, Anita Liberalesso Neri focaliza as principais contribuições de diversas áreas da psicologia, básicas e de aplicação, para o estudo e intervenção no campo do envelhecimento no Brasil. Ressalta que não se deve considerar a velhice de forma preconceituosa e sugere linhas de intervenção, visando à qualidade de vida na velhice.

No capítulo 2, Meire Cachioni e Anita L. Neri tratam de programas educacionais em universidades como facilitadores do envelhecimento bem-sucedido, destacando a necessidade do idoso de compreender um mundo em transformação, incrementar conhecimentos teóricos e práticos, satisfazer preocupações de ordem cultural, ampliar suas relações sociais e participar autônoma e ativamente na sociedade. Apresentam um histórico dos modelos de programas de Universidades da Terceira Idade, a partir de 1960, em países como França, Bélgica, Suíça, entre outros, e a partir de 1980 no Brasil. Mencionam dois estudos brasileiros que comprovam a utilidade desse modelo de educação nãoformal, mas alertam para a necessidade de formação de profissionais especializados.

No 3o capítulo, Andréa Cristina Garofe Fortes e Anita L. Neri discutem os eventos de vida (esperados ou inesperados) na construção da trajetória individual, considerando as influências positivas e negativas e a medida em que o ser humano controla tais eventos. São apresentadas definições, com base em autores distintos, e formas de tratá-los, de acordo com o interesse metodológico e o paradigma que sustenta o conceito.

O capítulo 4 veicula dados de uma pesquisa brasileira (Capitanini e Neri) sobre solidão e bem-estar na velhice, a qual teve como objetivos descrever as relações entre condições de vida, características das relações sociais e sentimentos de isolamento e solidão, bem como o bem-estar subjetivo em mulheres idosas que vivem sós. Os resultados mostram que, para $75 \%$ delas, essa condição não as faz se descreverem como isoladas, e atribuem o bem-estar na velhice à capacidade de recorrer a mecanismos compensatórios como trabalho e envolvimento em atividades sociais. No geral, os dados vão ao encontro de pesquisas nacionais e internacionais, que rejeitam o estigma de que o idoso é infeliz, só, abandonado e doente e sugerem que experiências de bem-estar são fortemente influenciadas pelas qualidades do self e por variáveis sociocognitivas.

As autoras Samila Sathler Tavares, Anita L. Neri e Ana Paula Cupertino citam, no 5o capítulo, uma revisão de trabalhos empíricos e teóricos, nacionais e internacionais, sobre aposentadoria, depressão e velhice bem-sucedida. Hoje, com o aumento da expectativa de vida e com a possibilidade de um período maior na condição de aposentado, espera-se que o indivíduo faça desta um período de desenvolvimento e não de ajuste a uma nova condição. Depressão não é a única condição emocional possível na velhice, dizem as autoras, já que perdas decorrentes do aumento da idade não necessariamente geram declínio nos aspectos psicoemocionais. Surpreendem noticiando que a aposentadoria não causa depressão na velhice, podendo ser enfrentada sem grandes implicações emocionais, quando vivenciada

\footnotetext{
${ }^{1}$ Endereço para correspondência:

E-mail: marinalbn@lexxa.com.br
} 
como um acontecimento esperado.

Mônica Sanches Yassuda apresenta, no capítulo 6, uma integração de resultados de pesquisas que procuraram investigar a influência do controle percebido sobre a memória e o desempenho, tema pouco pesquisado no Brasil, que demanda mais estudos que precisem efetivamente esta influência nesta população. Traz a definição e a teoria subjacente aos conceitos-base para o estudo da relação mencionada: auto-eficácia, metamemória, foco de controle e teoria de atribuição. Mostra que a auto-eficácia para memória é mais baixa em idosos; quanto maior ela for, melhor o desempenho de memória; que a metamemória também se correlaciona positivamente, porém de forma mais modesta, com o desempenho de memória; e que o idoso apresenta um padrão de atribuição menos adaptativo que o de pessoas mais jovens, o que pode influenciar negativamente seu desempenho de memória. No capítulo 7, Roosevelt Leão Júnior e Marineia Crosara de Resende também trazem teorias e pesquisas sobre auto-eficácia no entendimento do desempenho de memória do idoso e ressaltam a necessidade de estudos sobre a relação auto-eficácia e memória.

Elisandra Villela Gasparetto Sé, Nelma Caíres Queiroz e Mônica S. Yassuda analisam, no capítulo 8, aspectos do funcionamento normal e patológico da memória e as modificações morfológicas e funcionais do cérebro no idoso, associadas ou não a disfunções cognitivas. Apresentam definições, causas e conseqüências das demências mais freqüentes em idosos, como a Doença de Alzheimer, a de Parkinson, entre outras.

No capítulo 9, Paulo Renato Canineu, Maria Cibele Silva e Benito Pereira Damasceno discutem a hospitalização psiquiátrica, a incidência e as implicações das demências mais freqüentes no contexto em questão, em diversos países, incluindo o Brasil. Enfatizam a necessidade do diagnóstico correto e precoce, com o objetivo de possibilitar um envelhecimento digno e evitar que se confunda um quadro de demência com envelhecimento malsucedido.

No capítulo 10, José Eduardo Martinelli e Ivan Aprahamian apresentam o Teste do Desenho do Relógio, ferramenta de triagem em casos de suspeita de quadros demenciais. Utilizado concomitantemente a outros instrumentos de avaliação das funções neuropsiquiátricas, dizem os autores, o teste é sensível para captar alterações nas funções dos lobos frontal, parietal e temporal (funções visuoespacial, mnemônica, lingüística e executiva). Os resultados podem ser obtidos por meio de uma entre as 15 escalas validadas, entretanto, os autores apontam que esta vasta possibilidade de interpretação de um simples teste de triagem indica que talvez sua análise não seja tão simples e que não haja consenso quanto ao melhor método de interpretação, sendo essas as maiores desvantagens relacionadas ao uso do Teste do Desenho do Relógio.

Por fim, Flávia Rodrigues Brandão e Paulo Dalgalarrondo apresentam, no último capítulo, 12 instrumentos de avaliação que diagnosticam quadros de delirium. Os instrumentos possibilitam uma complementação de uma anamnese, haja vista que o diagnóstico desse quadro demanda uma avaliação clínica criteriosa em virtude das implicações etiológicas e terapêuticas da síndrome. $\mathrm{O}$ quadro caracteriza-se basicamente por distúrbios das funções cognitivas e da consciência; em sua etiologia multifatorial são apontados os fatores predisposição (doenças clínicas graves, distúrbios cognitivos ou sensoriais) e os precipitantes ou agentes agressivos (uso de medicações, álcool, drogas, abstinência destas substâncias, procedimentos cirúrgicos de grande porte, privação de sono). Segundo, os autores, com um diagnóstico correto a causa orgânica poderá ser tratada e os riscos de morbidade e mortalidade e o tempo de internação poderão ser diminuídos. Os instrumentos podem ser de rastreamento, seleção dos subtipos de delirium, para a realização diagnóstica ou aqueles que permitem a análise da evolução do quadro.

Considero que o livro fornece de forma clara e abrangente, inclusive para leigos no assunto, um panorama sobre conceitos, teorias e estudos relacionados à velhice, bem como traz soluções para que indivíduo e ambiente possam ter a possibilidade, cada vez maior, de uma velhice bem-sucedida.

Recebido em maio de 2004 Aprovado em junbo de 2004

Sobre a autora:

Marina Liberalesso Neri é psicóloga e mestranda pelo Programa de Estudos Pós-Graduados em Psicologia da Universidade São Francisco. 